\title{
Peertechz
}

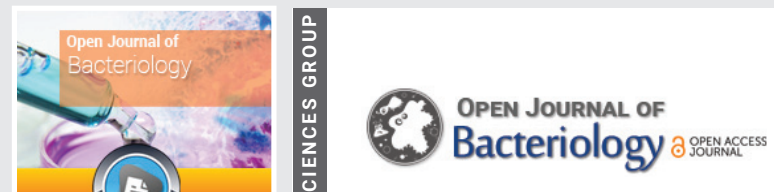

\section{Application of diophantine equations for practical problems solution in biology}

\author{
Sergey P Klykov ${ }^{1,2 *}$ \\ ${ }^{1}$ Fermentation Expert, Poste Restante, Obolensk, Serpukhov district, Moscow Region, 142279, Russia \\ ${ }^{2}$ Alpha-Integrum, Ltd, Russia
}

Received: 14 April, 2021

Accepted: 24 May, 2021

Published: 26 May, 2021

*Corresponding author: Sergey P Klykov, Fermentation expert, Poste Restante, Obolensk, Serpukhov district, Moscow Region, Russia,

E-mail:smlk03@mail.ru, klykov10@gmail.com

Keywords: Golden ratio; Golden section; Diophantine equations; Fermat's last theorem; Pythagorean primitive triples; Fermentation; S-shaped growth curves of bacteria; Modeling

https://www.peertechzpublications.com

\section{Check for updates}

\begin{abstract}
An attempt was made to use the Diophantine equations for the analysis of S-shaped curves of the growth of microorganisms. The most famous of such equations are the equation of the Pythagorean Theorem and the equation of Fermat's Last Theorem, FLT. The article does not claim to prove FLT, but it shows interesting facts for biological objects - there are cells of microorganisms that are growing according to the S-shaped growth curve. It was shown by using of an elementary algebra that the solution of the equation $a^{n}+b^{n}=c^{n}$ cannot simultaneously have three integer nonzero roots "a", "b" and "c" for integers $n>2$. It was shown, that the same unsolvable situation can accompany the analysis if $n=2$. Last case occurs due to the fact that the irreducible complexity containing the major, $\Phi$, and minor, $\varphi$, numbers is always preserved for pairs of numbers with "a" and "c", or with "b" and "c". An attempt of practical application in biology of the found patterns were shown as a hypothesis, which has a fairly plausible explanation using the models used for the analysis in this paper.
\end{abstract}

\section{Introduction}

The Fermat's theorem is one of the most popular theorems in mathematics. Its condition is formulated simply at the school arithmetic level. However, many mathematicians and laymen have been looking for the proof of the theorem for more than three hundred years. This theorem says that at the same time there are no nonzero integers "a", "b", "c", "n", for $n>2$, which would satisfy the equation:

$$
a^{\mathrm{n}}+\mathrm{b}^{\mathrm{n}}=\mathrm{c}^{\mathrm{n}} \text {, }
$$

It was proved in 1994 by A. Wiles and colleagues, [1]. The proposed proof is very good for understanding in a narrow mathematical community. However, we can say that not all specialists in mathematics understand this. Simplification is necessary for a wider range of stakeholders.

For this reason, in particular, an analysis was made and an article was published, [2], in which it was shown that equations with square roots and roots with any degrees from differences can be broken/decomposed up into different terms. This is equation (143) in this article. It was impossible to neglect the attempt to connect the obtained results with the verification of the Fermat's theorem.
Mathematical modeling in biotechnology, [ 2 and literature in this article] changed its course since last 3-4 decades with a shift toward situation-specific, complex treatments as opposed to causal, mechanistic and general analyses as in the past. Common patterns/theories of a cell population growth do not receive much emphasis unlike in the past, specifically the well-known variations from Monod's model. On the other hand, development of fermentation technology focused only on improving fermenter technology and automation. Thus, the mathematical and physical (biological) problems of microbial growth and biosynthesis, both in the general case as well as in specific applications, remained unattended too.

The author of this article published a preprint, [3], with his own proof of FLT, which at the time of the writing has not yet received serious objections to the presented proof of FLT, despite the fairly wide distribution of this preprint among the professional community of "pure mathematics".

\section{Some details for Fermat's Last Theorem}

\subsection{Background information}

2.1.1 The Equation (143) from [2],




$$
\mathrm{a}=\left(\mathrm{c}^{\mathrm{n}}-\mathrm{b}^{\mathrm{n}}\right)^{(1 / \mathrm{n})}=(\varepsilon / \gamma)^{(1 / \mathrm{n})}\left[\left(\mathrm{c}^{\mathrm{n}}\right)^{(1 / \mathrm{n})} \Phi^{(\mathrm{n}-1) / \mathrm{n}}-\varphi^{(\mathrm{n}-1) / \mathrm{n}}\left(\left(\mathrm{b}^{\mathrm{n}}\right) / \gamma\right)^{1 / \mathrm{n}}\right]
$$

Naturally, the inverse calculation of " $b$ " through " $a$ " is also possible.

2.1.2 $\langle a \gg,\langle\langle\mathrm{b} \gg,\langle\langle\mathrm{c} \gg,\langle\mathrm{n} \gg$ are integers for the case considered in this article, and $\mathrm{a}=\mathrm{pA}, \mathrm{b}=\mathrm{pB}, \mathrm{c}=\mathrm{pC}$, where " $\mathrm{p}$ " is any other integer. The Pythagorean primitive triples " $\mathrm{A}$ ", " $\mathrm{B}$ ", " $\mathrm{C}$ " are the minimum integers greater than 1 that satisfy to the condition (1), as well as the numbers "a", "b" and "c", moreover, $\mathrm{a}<\mathrm{b}$ and $\mathrm{c}>\mathrm{b}$;

2.1.3 $\mathrm{C}_{0}=\mathrm{C}^{\mathrm{n}} / \Phi^{2}$ is the ratio of $\mathrm{C}^{\mathrm{n}}$ to the number $\Phi^{2}$, where $\Phi=1 / \varphi=1 / 0.6180339 \ldots=1.6180339 \ldots$

$$
\text { 2.1.4 } \gamma_{\mathrm{A}}=\mathrm{A}^{\mathrm{n}} / \mathrm{C}_{0} \text {, }
$$

and

$$
\gamma_{\mathrm{B}}=\mathrm{B}^{\mathrm{n}} / \mathrm{C}_{0}
$$

Here the indices " $A$ " or " $B$ " with the numbers " $\gamma$ " indicate through which parameter this " $\gamma$ " is calculated. Accordingly, for the " $\gamma_{A}$ " value, the calculation was carried out through the parameter " $\mathrm{A}$ " for the further purpose of the " $\mathrm{B}$ " value study and vice versa. Naturally, it is possible to use $\langle a \mathrm{a}\rangle,\langle\mathrm{b}\rangle,\langle\langle\mathrm{c}\rangle$ to determine $\gamma_{\mathrm{a}}$ and $\gamma_{\mathrm{b}}$;

$$
\text { 2.1.5 } \varepsilon=\Phi \gamma-\phi \gamma^{2}
$$

The values obtained in accordance with paragraph 2.1.4. are used for calculations in Equation (5).

2.1.6 The calculation results for paragraphs 2.1.2.-2.1.5. shown in the Table 1.

\subsection{Solution of the Equation (2) for different $n$}

2.2.1 Let the first term on the right of the Equation (2) be $\ll L \gg$ and the second term on the equation be $\langle M M \gg$.

$$
\begin{aligned}
& \text { i.e., } L_{A}=\left(\Phi^{n}-\Phi^{n-2} \gamma_{A}\right)^{1 / n} C \text {, } \\
& \text { and } L_{B}=\left(\Phi^{n}-\Phi^{n-2} \gamma_{B}\right)^{1 / n} C,
\end{aligned}
$$

The Equations (6) and (7) were obtained at simplifying of the first term in the right-hand side of equation (2). Calculations are made through " $\mathrm{A}$ " or " $\mathrm{B}$ " upon receipt of values corresponding to " $\mathrm{B}$ " or " $\mathrm{A}$ ". That is, the Equation (3) is used in the analysis of " $B$ " values, and the Equation (4) is used in the analysis of " $\mathrm{A}$ " values. Accordingly, the values with the corresponding indices " $\mathrm{L}_{A}$ " and/or " $\mathrm{L}_{B}$ " in the form of the Equations (6) and (7) were obtained after simplification.

The Equations for the quantities " $M_{A}$ " and " $M_{B}$ " were also obtained similarly to the Equations (6) and (7):

$$
\begin{aligned}
& M_{A}=\left(\phi^{n-2} / \gamma_{A}-\phi^{n}\right)^{1 / n} A, \\
& \text { and } M_{B}=\left(\phi^{n-2} / \gamma_{B}-\phi^{n}\right)^{1 / n} B,
\end{aligned}
$$

2.2.2 The joint solution of the Equations (6), (8) and (7), (9) by equating the factors " $\gamma_{A}$ " and " $\gamma_{B}$ " in each of the corresponding equations allows us to write the following expressions:

$$
\Phi^{n} C^{n} / L_{A}{ }^{n}-\varphi^{n} A^{n} / M_{A}{ }^{n}=1,
$$

and

$$
\Phi^{n} C^{n} / L_{B}{ }^{n}-\varphi^{n} B^{n} / M_{B}{ }^{n}=1,
$$

2.2.3 The Equations (10) and (11) can be represented as follows:

$\left(\Phi^{\mathrm{n} / 2} \mathrm{C}^{\mathrm{n} / 2} / \mathrm{L}_{\mathrm{A}} \mathrm{n} / 2-\phi^{\mathrm{n} / 2} \mathrm{~A}^{\mathrm{n} / 2} / \mathrm{M}_{\mathrm{A}}{ }^{\mathrm{n} / 2}\right)\left(\Phi^{\mathrm{n} / 2} C^{\mathrm{n} / 2} / \mathrm{L}_{\mathrm{A}}{ }^{\mathrm{n} / 2}+\phi^{\mathrm{n} / 2} \mathrm{~A}^{\mathrm{n} / 2} / \mathrm{M}_{\mathrm{A}}{ }^{\mathrm{n} / 2}\right)=1$,

and $\quad\left(\Phi^{n / 2} C^{n / 2} / L_{B}^{n / 2}-\varphi^{n / 2} B^{n / 2} / M_{B}^{n / 2}\right) \quad\left(\Phi^{n / 2} C^{n / 2} / L_{B}^{n / 2}+\phi^{n / 2} B^{n / 2} /\right.$ $\left.M_{B}^{n / 2}\right)=1$,

2.2.4 The solution of the Equations (12) and (13) for $n=2$ and other values completely excludes $\Phi$ and $\phi$, if we take into account the Equations from sections 2.1.1.-2.1.4. and 2.2.12.2.2. This allows us to express the Equations (12) and (13) only by the integers " $\mathrm{A}$ ", " $\mathrm{B}$ " and " $\mathrm{C}$ " according to the Equations:

$\left(\mathrm{k}_{\mathrm{A}}^{-} \quad \mathrm{k}_{\mathrm{A}}^{+}\right)=\left\{\mathrm{C} /\left[\left(\mathrm{C}^{2}-\mathrm{A}^{2}\right)^{1 / 2}\right]-\mathrm{A} /\left[\left(\mathrm{C}^{2}-\mathrm{A}^{2}\right)^{1 / 2}\right]\right\}\left\{\mathrm{C} /\left[\left(\mathrm{C}^{2}-\mathrm{A}^{2}\right)^{1 / 2}\right]+\mathrm{A} /\right.$ $\left.\left[\left(\mathrm{C}^{2}-\mathrm{A}^{2}\right)^{1 / 2}\right]\right\}=1$,

and

$\left(\mathrm{k}_{\mathrm{B}}^{-} \quad \mathrm{k}^{+}{ }_{\mathrm{B}}\right)=\left\{\mathrm{C} /\left[\left(\mathrm{C}^{2}-\mathrm{B}^{2}\right)^{1 / 2}\right]-\mathrm{B} /\left[\left(\mathrm{C}^{2}-\mathrm{B}^{2}\right)^{1 / 2}\right]\right\}\left\{\mathrm{C} /\left[\left(\mathrm{C}^{2}-\mathrm{B}^{2}\right)^{1 / 2}\right]+\mathrm{B} /\right.$ $\left.\left[\left(\mathrm{C}^{2}-\mathrm{B}^{2}\right)^{1 / 2}\right]\right\}=1$, (15).

2.2.4.1 It is obvious, the values " $\mathrm{k}^{-}$" and " $\mathrm{k}$ " will belong to rational fractions or integers if " $\mathrm{A}$ ", " $\mathrm{B}$ " and " $\mathrm{C}$ " are integers. Moreover, $\mathrm{k}^{-}<1$ and $\mathrm{k}^{+}>1$. This is shown in Table 2 .

Thus,

$\mathrm{k}_{\mathrm{B}}^{-}=1 / \mathrm{A}$,

and

$\mathrm{k}_{\mathrm{B}}^{+}=\mathrm{A}$,

if the primitive triples " $\mathrm{A}$ ", " $\mathrm{B}$ " and " $\mathrm{C}$ " are defined by the Equations:

$\mathrm{B}=\left(\mathrm{A}^{2}-1\right) / 2$,

and

$\mathrm{C}=\left(\mathrm{A}^{2}+1\right) / 2$,

for example.

2.2.4.2 The difference between "L" and " $M$ " gives the integers " $A$ " and " $B$ ", respectively, for pairs of numbers " $L_{B}$ " - " $M_{B}$ " and " $L_{A}$ " - " $M_{A}$ ". It can be seen in the Table 2.

2.2.5 The solution of equations (12) and (13) for $n=3$ and other conditions $n>2$ gives irrational values, if we will take into account the Equations from sections 2.1.1.-2.1.4. and 2.2.12.2.2., and this prohibits the possibility of obtaining solutions that consist of integers for the given cases, see Table 1.

\section{Practical Application and Evidence in the Nature}

The Equation (18) in the article [2], devoted to the binary 
Table 1: The parameters of the Equation (2), which are determined for $A^{n}+B^{n}=C^{n}$.

\begin{tabular}{|c|c|c|c|c|c|c|c|c|c|c|c|c|c|c|c|c|}
\hline \multirow{2}{*}{$\#$} & 1 & 2 & 3 & 4 & 5 & 6 & 7 & 8 & 9 & 10 & 11 & 12 & 13 & 14 & 15 & 16 \\
\hline & $\mathbf{n}$ & C & B & A & $\mathbf{C}^{n}$ & $\mathbf{B}^{\mathrm{n}}$ & $A^{n}$ & $\mathrm{X}_{0}$ & $Y_{B}$ & $\mathrm{Y}_{\mathrm{A}}$ & $\varepsilon_{\mathrm{B}}=\Phi \mathrm{Y}_{\mathrm{B}}-\varphi \mathrm{Y}_{\mathrm{B}}^{2}$ & $\varepsilon_{A}=\Phi Y_{A}-\varphi Y_{A}^{2}$ & $\varepsilon_{\mathrm{B}} / \mathrm{Y}_{\mathrm{B}}$ & $\varepsilon_{\mathrm{A}} / \mathrm{Y}_{\mathrm{A}}$ & $A(E q .(2))$ & $B(E q .(2))$ \\
\hline 1 & 2 & 5 & 4 & 3 & 25 & 16 & 9 & 9.55 & 1.68 & 0.94 & 0.98 & 0.98 & 0.58 & 1.04 & 3 & 4 \\
\hline 2 & 2 & 13 & 12 & 5 & 169 & 144 & 25 & 64.55 & 2.23 & 0.39 & 0.53 & 0.53 & 0.24 & 1.38 & 5 & 12 \\
\hline 3 & 2 & 25 & 24 & 7 & 625 & 576 & 49 & 238.73 & 2.41 & 0.21 & 0.31 & 0.31 & 0.13 & 1.49 & 7 & 24 \\
\hline 4 & 2 & 41 & 40 & 9 & 1681 & 1600 & 81 & 642.08 & 2.49 & 0.13 & 0.19 & 0.19 & 0.08 & 1.54 & 9 & 40 \\
\hline 5 & 2 & 61 & 60 & 11 & 3721 & 3600 & 121 & 1421.30 & 2.53 & 0.09 & 0.13 & 0.13 & 0.05 & 1.57 & 11 & 60 \\
\hline 6 & 2 & 85 & 84 & 13 & 7225 & 7056 & 169 & 2759.70 & 2.56 & 0.06 & 0.10 & 0.10 & 0.04 & 1.58 & 13 & 84 \\
\hline 7 & 2 & 113 & 112 & 15 & 12769 & 12544 & 225 & 4877.32 & 2.57 & 0.05 & 0.07 & 0.07 & 0.03 & 1.59 & 15 & 112 \\
\hline 8 & 2 & 145 & 144 & 17 & 21025 & 20736 & 289 & 8030.84 & 2.58 & 0.04 & 0.06 & 0.06 & 0.02 & 1.60 & 17 & 144 \\
\hline 9 & 2 & 89 & 80 & 39 & 7921 & 6400 & 1521 & 3025.6 & 2.12 & 0.50 & 0.66 & 0.66 & 0.31 & 1.31 & 39 & 80 \\
\hline 10 & 2 & 17 & 15 & 8 & 289 & 225 & 64 & 110.39 & 2.04 & 0.58 & 0.73 & 0.73 & 0.36 & 1.26 & 8 & 15 \\
\hline 11 & 2 & 85 & 77 & 36 & 7225 & 5929 & 1296 & 2759.70 & 2.15 & 0.47 & 0.62 & 0.62 & 0.29 & 1.33 & 36 & 77 \\
\hline 12 & 2 & 53 & 45 & 28 & 2809 & 2025 & 784 & 1072.94 & 1.89 & 0.73 & 0.85 & 0.85 & 0.45 & 1.17 & 28 & 45 \\
\hline 13 & 2 & 65 & 63 & 16 & 4225 & 3969 & 256 & 1613.81 & 2.46 & 0.16 & 0.24 & 0.24 & 0.10 & 1.52 & 16 & 63 \\
\hline 14 & 1 & 3 & 2 & 1 & 3 & 2 & 1 & 1.15 & 1.75 & 0.87 & 0.94 & 0.94 & 0.54 & 1.08 & 1 & 2 \\
\hline 15 & 3 & 11 & 7 & 3 & 1331 & 343 & 27 & 508.40 & 0.67 & 0.05 & 0.81 & 0.08 & 1.20 & 1.59 & 9.96 & 10.93 \\
\hline 16 & 2 & 10 & 8 & 6 & 100 & 64 & 36 & 38.20 & 1.68 & 0.94 & 0.98 & 0.98 & 0.58 & 1.04 & 6 & 8 \\
\hline
\end{tabular}

Columns 3 and 4 were used to calculate all parameters for a given «C $»$ value in the column 2 . Bold in columns 15 and 16 are the roots, which were obtained by solving the Equation (2) for a given «C» value from the $2^{\text {nd }}$ column. Lines 1-15 correspond to $p=1$, line 16

corresponds $\mathrm{p}=2$

Table 2: Parameters $\mathrm{L}, \mathrm{M}, \mathrm{k}$ - and $\mathrm{k}+$ for the corresponding data $\mathrm{A}, \mathrm{B}, \mathrm{C}$ and $\mathrm{n}$ in Table 1

\begin{tabular}{|c|c|c|c|c|c|c|c|c|c|c|c|c|c|c|c|c|}
\hline \multirow{2}{*}{$\#$} & 1 & 2 & 3 & 4 & 5 & 6 & 7 & 8 & 9 & 10 & 11 & 12 & 13 & 14 & 15 & 16 \\
\hline & $n$ & C & B & A & $A(E q .(2))$ & B(Eq.(2)) & $L_{B}$ & $M_{B}$ & $\mathbf{k}_{\mathrm{B}}$ & $\mathbf{k}_{B}^{+}$ & $\mathrm{L}_{\mathrm{A}}$ & $M_{A}$ & $\mathrm{k}_{\mathrm{A}}$ & $k_{A}^{+}$ & $L_{B}-M_{B}$ & $L_{A}-M_{A}$ \\
\hline 1 & 2 & 5 & 4 & 3 & 3 & 4 & 4.85 & 1.85 & 0.33 & 3.00 & 6.47 & 2.47 & 0.50 & 2.00 & 3 & 4 \\
\hline 2 & 2 & 13 & 12 & 5 & 5 & 12 & 8.09 & 3.09 & 0.20 & 5.00 & 19.42 & 7.42 & 0.67 & 1.50 & 5 & 12 \\
\hline 3 & 2 & 25 & 24 & 7 & 7 & 24 & 11.33 & 4.33 & 0.14 & 7.00 & 38.83 & 14.83 & 0.75 & 1.33 & 7 & 24 \\
\hline 4 & 2 & 41 & 40 & 9 & 9 & 40 & c14.56 & 5.56 & 0.11 & 9.00 & 64.72 & 24.72 & 0.80 & 1.25 & 9 & 40 \\
\hline 5 & 2 & 61 & 60 & 11 & 11 & 60 & 17.80 & 6.80 & 0.09 & 11.00 & 97.08 & 37.08 & 0.83 & 1.20 & 11 & 60 \\
\hline 6 & 2 & 85 & 84 & 13 & 13 & 84 & 21.03 & 8.03 & 0.08 & 13.00 & 135.91 & 51.91 & 0.86 & 1.17 & 13 & 84 \\
\hline 7 & 2 & 113 & 112 & 15 & 15 & 112 & 24.27 & 9.27 & 0.07 & 15.00 & 181.22 & 69.22 & 0.88 & 1.14 & 15 & 112 \\
\hline 8 & 2 & 145 & 144 & 17 & 17 & 144 & 27.51 & 10.51 & 0.06 & 17.00 & 233.00 & 89.00 & 0.89 & 1.12 & 17 & 144 \\
\hline 9 & 2 & 89 & 80 & 39 & 39 & 80 & 63.10 & 24.10 & 0.23 & 4.33 & 129.44 & 49.44 & 0.63 & 1.60 & 39 & 80 \\
\hline 10 & 2 & 17 & 15 & 8 & 8 & 15 & 12.94 & 4.94 & 0.25 & 4.00 & 24.27 & 9.27 & 0.60 & 1.67 & 8 & 15 \\
\hline 11 & 2 & 85 & 77 & 36 & 36 & 77 & 58.25 & 22.25 & 0.22 & 4.50 & 124.59 & 47.59 & 0.64 & 1.57 & 36 & 77 \\
\hline 12 & 2 & 53 & 45 & 28 & 28 & 45 & 45.30 & 17.30 & 0.29 & 3.50 & 72.81 & 27.81 & 0.56 & 1.80 & 28 & 45 \\
\hline 13 & 2 & 65 & 63 & 16 & 16 & 63 & 25.89 & 9.89 & 0.13 & 8.00 & 101.94 & 38.94 & 0.78 & 1.29 & 16 & 63 \\
\hline 14 & 1 & 3 & 2 & 1 & 1 & 2 & 1.62 & 0.62 & 1.00 & 5.00 & 3.24 & 1.24 & 1.41 & 2.83 & 1 & 2 \\
\hline 15 & 3 & 11 & 7 & 3 & 9.96 & 10.93 & 16.12 & 6.16 & 0.13 & 0.57 & 17.68 & 6.75 & 0.22 & 0.39 & 9.96 & 10.93 \\
\hline 16 & 2 & 10 & 8 & 6 & 6 & 8 & 9.71 & 3.71 & 0.33 & 3.00 & 12.94 & 4.94 & 0.50 & 2.00 & 6 & 8 \\
\hline
\end{tabular}

doubling in microbial populations at a slow growth phase, is the initial equation for the consideration in this article:

$$
\mathrm{K}^{\prime}=\left(\mathrm{X}_{\mathrm{p}}-\mathrm{X}_{\mathrm{Lim}}\right) \mathrm{X}_{\text {Lim }}^{\mathrm{st}}
$$

where $\mathrm{K}$ 'is a constant; $\mathrm{X}_{\mathrm{p}}$ is a certain value equal to the asymptote during population growth in the decaying growth phase; $X_{\mathrm{Lim}}$ is the number of cells at the interface between the exponential phase of population growth and the phase of damped growth; $\mathrm{X}_{\text {Lim }}^{\text {st }}$ - the number of non-dividing cells at the age of 0 cell cycle. The main premise of this microorganism growth model (IMMD) is the assumption that the total number of cells, $\mathrm{X}$, is always determined by the sum of non-dividing cells, $\mathrm{X}^{\mathrm{st}}$, and dividing cells, $\mathrm{X}^{\mathrm{div}}$ :

$$
\mathrm{X}=\mathrm{X}^{\mathrm{st}}+\mathrm{X}^{\mathrm{div}} \text {, }
$$

An analysis of the Equations (20) and (21) according to the scheme in paragraph 2 of this article shows that if $\mathrm{X}$ values belong to the set of integers, then $\mathrm{X}^{\mathrm{st}}$ and $\mathrm{X}^{\mathrm{div}}$ values can belong to the set of irrational numbers. It is obviously for $\mathrm{X}$, if that value is expressed by integers, then this number can be the square of another integer, $\mathrm{C}=\mathrm{X}^{1 / 2}$. The numbers $\mathrm{X}^{\text {st }}$ and $\mathrm{X}^{\mathrm{div}}$ can have irrational values $\mathrm{A}=\left(\mathrm{X}^{\mathrm{st}}\right)^{1 / 2}$ and $\mathrm{B}=\left(\mathrm{X}^{\mathrm{div}}\right)^{1 / 2}$, except for the $\tau_{\text {Final }}$ value, when $X_{\text {Final }}=X_{\text {Final }}^{\text {st }}$ and $X^{\text {div }} F_{\text {inal }}=0$, [2]. The biological significance of this phenomenon can only be explained by the fact that there is no sharp boundary between the properties of $\mathrm{X}^{\text {st }}$ and $\mathrm{X}^{\mathrm{div}}$ cells, which are close in the age of its cell cycles. This refers to the situation if 2 daughter cells have just come from one parent cell and one of them has entered into the $\mathrm{X}^{\text {div }}$ state through some small time interval compared to the doubling time, $\mathrm{t}_{\mathrm{d}}$, and the second has remained in the $\mathrm{X}^{\text {st }}$ state.

But, it is obvious, the Equations (12) and (13) can also have integer solutions according to paragraph 2 . This is acceptable for the case if we assume that $\mathrm{C}=\mathrm{X}^{1 / 2}$ and $\mathrm{B}=\left(\mathrm{X}^{\text {new }}\right)^{1 / 2}$, where the $X^{\text {new }}$ values should be considered as "new" cells, [2], which were formed after some fixed reference time. For example, after a time corresponding to the time for the boundary between the exponential growth phase and the slow growth phase, $\tau_{\text {Lim }}$ 
Accordingly, cells, which were already existing in a population at the given time, $\tau_{\text {Lim }}$, are "old" cells, $\mathrm{X}^{\text {old }}$, [2]. Moreover, $\mathrm{A}=$ $\left(\mathrm{X}^{\text {old }}\right)^{1 / 2}$, where A values is also an integer, like $\langle\mathrm{C} \gg$ and $\langle\mathrm{B}\rangle$ values. At $\tau=\tau_{\text {Final }}$, both components, $\mathrm{X}^{\text {new }}$ or $\mathrm{X}^{\text {old }}$, cannot be equal to 0 .

It's obvious that:

$$
\mathrm{X}=\mathrm{X}^{\text {old }}+\mathrm{X}^{\text {new }} \text {, }
$$

Thus, the equality is true:

$$
\left(\mathrm{X}^{\mathrm{st}}+\mathrm{X}^{\mathrm{div}}\right) /\left(\mathrm{X}^{\text {old }}+\mathrm{X}^{\text {new }}\right)=1 \text {, }
$$

Indeed, the Equations (24) - (27) below gives the solutions of the Equation (23):

$$
\begin{aligned}
& X=X_{p}-\left(X_{p}-X_{L i m}\right) e^{[-(m / a)(\tau-\tau L i m)]}, \\
& X^{\text {div }}=X-X^{s t}=X-K^{\prime} /\left(X_{p}-X\right), \\
& X^{\text {Old }}=X_{L i m} e^{[-(m / a)(\tau-\tau L i m)]}, \\
& X^{\text {new }}=X_{p}\left(1-e^{[-(m / 2)(\tau-\tau L i m)]}\right),
\end{aligned}
$$

where «m» and «a and trophic coefficient (it is not the same as the «a» value used above in the Equations (1) and (2)). The Equations (26) and (27) were firstly shown in [4], however, with an incorrect interpretation like $\mathrm{X}^{\mathrm{div}}$ and $\mathrm{X}^{\text {st }}$, respectively.
Taking into account all the equations of this article and article [2], it was shown that the development of populations can be determined by the Fermat's theorem and the Pythagorean Theorem, as a special case of Fermat's theorem. The reason is: there are no other possibilities for the Nature, except $n=2$.

\section{Conclusion}

The Fermat's theorem and Pythagorean Theorem can be used by a relatively simple algebraic way to analyze S-shaped growth curves of microorganisms.

Application in practical biology for describing of population growth was proposed to show essential features in interpretations of belonging to different groups of cells.

\section{References}

1. Andrew Wiles (1995) Modular elliptic curves and Fermat's last theorem. Annals of Mathematics Journal 141: 443-551. Link: https://bit.ly/3vnIGIW

2. Sergey P Klykov (2020) S-shaped growth curves in fermentations and golden ratio. International Journal of Biomathematics 13: 30.

3. Sergey P. Klykov (2021) On the issue of the relationship between fermat's last theorem, flt, and the pythagorean theorem. DOI:10.13140/RG.2.2.36466.02243 Link: https://bit.ly/3wxriRW

4. Biryukov VV (2011) A Structurized Model for Biomass Growth during OxygenLimited Fermentation Biotechnology 4: 65-72.

\section{Discover a bigger Impact and Visibility of your article publication with}

Peertechz Publications

Highlights

* Signatory publisher of ORCID

* Signatory Publisher of DORA (San Francisco Declaration on Research Assessment)

* Articles archived in worlds' renowned service providers such as Portico, CNKI, AGRIS, TDNet, Base (Bielefeld University Library), CrossRef, Scilit, J-Gate etc

* Journals indexed in ICMJE, SHERPA/ROMEO, Google Scholar etc.

* OAI-PMH (Open Archives Initiative Protocol for Metadata Harvesting)

* Dedicated Editorial Board for every journal

* Accurate and rapid peer-review process

* Increased citations of published articles through promotions

* Reduced timeline for article publication

Submit your articles and experience a new surge in publication services (https://www.peertechz.com/submission).

Copyright: @ 2021 Klykov SP. This is an open-access article distributed under the terms of the Creative Commons Attribution License, which permits unrestricted use, distribution, and reproduction in any medium, provided the original author and source are credited. 